\title{
The Aesthetic Revival
}

\section{LACHLAN MACDOWALL}

UNIVERSITY OF MELBOURNE

\author{
Beth Hinderliter, William Kaizen, Vered Maison, Jaleh Mansoor and Seth \\ McCormick (eds) \\ Communities of Sense: Rethinking Aesthetics and Politics \\ Duke University Press, Durham \& London, 2009 \\ ISBN 9780822345138 \\ RRP US\$26.95 (pb)
}

This wide-ranging collection is built around a newly published essay by Jacques Rancière titled 'Contemporary Art and the Politics of Aesthetics' and a collection of papers from a conference with Rancière held at Columbia University nearly a decade ago. The delay in publication means that Rancière's piece, while a sharp summary of the major themes of his writing on art and politics, has been somewhat superseded by the release in English of three of his books on this topic: The Politics of Aesthetics (2004), Aesthetics and Its Discontents (2009) and Dissensus: On Politics and Aesthetics (2010).

Nevertheless, the collection succeeds in presenting a series of engaging essays that put Rancière's ideas to use in three broad areas: art criticism and aesthetic philosophy, forms of cultural history that engage with spatial categories, and political philosophies of community. While the contributors are somewhat 
homogenous in their institutional affiliations-most are senior faculty members in major US universities-their essays are diverse, ranging from re-readings of the history of Dada to the design of Bill Gate's house and the offices of Union Carbide, to pre- and post-Kantian notions of beauty and community. The collection ends with an interview with Ètienne Balibar, who argues for a countering of transnational violence with modes of civility, a move that mirrors this collection's attempt to reformulate the eighteenth-century notion of aesthetics-now wholly hollowed out, renovated and detached from its original-to new ends.

According to the editors, recent engagements with aesthetics have been marked by two poles: either a tradition of 'return to beauty' thinking, leading to a philosophical defence of autonomous notions of beauty, or the anti-aesthetic, a wholesale dismissal of aesthetic thinking as inevitably bourgeois. In these debates, 'aesthetics is thus celebrated as the basis for a new cosmopolitan universalism by the exponents of "beauty", or condemned as a bourgeois mystification by the adherents of the "anti-aesthetic"'. (5)

Rancière's project sits outside this antinomy. Instead, he offers a broad framework for thinking aesthetics as the relationship between 'forms of visibility' and 'patterns of intelligibility', what he terms the 'partition of the sensible'. (31) For Rancière, aesthetics, like politics, can be thought of as a spatialising category that gathers objects together, arranging them to produce appearances of similarity and coherence. The collection's title then refers less to the materiality of sense perception than to a more abstract 'sense of the common' that is created by the spatial arrangement of objects, a material partition also simultaneously functioning as a symbolic partition. (32) One key implication is that, while art remains a privileged domain of aesthetic production, aesthetics as a 'regime of identification' has a broader cultural relevance more familiar to cultural studies, as a 'polemical redistribution of objects and subjects, places and identities, spaces and times, visibilities and meanings'. (32)

The editors argue for the usefulness of Rancière's thinking in positioning and bypassing a range of contemporary debates in the relationship between art and politics: arguments about the nature of beauty (Dale Hickey, Arthur Danto, Elaine Scarry), the relationship between aesthetic and ethical criticism (Nicholas Bourriaud, Grant Kester, Claire Bishop) and the democratic potential of 
communitarian forms (Balibar, Laclau and Mouffe). For instance, in an essay about Louise Lawler's photography, Toni Ross provides a neat re-reading of some of the key debates on art and beauty from the last decade-after Rancière's chapter she is able to reverse and complicate the somewhat simplistic positions for which thinkers have come to stand. For instance, reading Bourriaud through Scarry, Ross notes how, despite Bourriaud renouncing a certain type of beauty in his concept of relational aesthetics, aesthetic judgements can be seen reappearing in the political dimensions of his thought in metaphors of 'intersubjective coexistences, cohabitation, and harmonious parity'. (86)

Rancière's conception of aesthetics also leads to a rethinking of the history of the term. He argues that it is not simply the case that an autonomous aesthetic sphere becomes implausible at the end of the twentieth century when:

new forms of social life and commodity culture, along with new techniques of production, reproduction, and communication, made it impossible to maintain the boundary between artistic production and technological reproduction, autonomous artworks and forms of commodity culture, high art and low art. (33)

Instead, we can look back past a Rauschenberg painting in which seemingly incongruous images collide to a description in Balzac's first novel over a century earlier in which, even at the supposed high point of aesthetic autonomy marked by the publication of Hegel's Lessons on Aesthetics, we can read of a curiosity shop in which 'crocodiles, apes and stuffed boas grinned at stained glass-windows, seemed to be about to snap at carved busts, to be running along lacquer-ware or to be clambering up chandeliers.' (35) For Rancière, this kind of blurring-the heterogeneous clumping and grouping-is not simply a feature of late modernism but is intrinsic to the category of aesthetics. This idea is taken up in an essay by Alexander Potts on the place of anti-aesthetic thinking in early nineteenth century aesthetic philosophy.

In Rancière's history of aesthetics, the claim for aesthetic autonomy is already linked to a desire for political autonomy. In its late eighteenth century emergence, after an era where the value of art was pre-organised according to privileged genres and themes, the idea of aesthetics implied 'that kind of equality that went along with the beheading of the King of France and the sovereignty of the people.' (37) But 
aesthetics also implied a second kind of equality, in which Art itself was dissolved into culture, suppressing itself, no longer existing as a separate activity. At the heart of this history of aesthetics is a paradox, reminiscent of Tony Bennett's account of aesthetics as the various social and governmental applications of the detached knowledge of the aesthetic, the 'uses of uselessness'.1 For Rancière, this paradox of art is both internal an inescapable: 'artwork's separateness promises the opposite: a life that will not know art as a separate practice and field of experience'. (38)

The rethinking of aesthetics as a field of intelligibility has particular implications for the kinds of art that can be made to appear, along with their political potential. A series of essays in the final section of the book challenge the dominance of archetypal communitarian forms in discussions of art and politics, what Yates McKee describes in an essay on the reception of Dziga Vertov as the 'avant-gardist paradigm of aesthetic autonomy, critical negativity, or collective immanence'. (289) Two essays in the collection by Carlos Basualdo and Reinaldo Laddaga and Rachel Haidu both nominate the precarious installations of Swiss artist Thomas Hirschhorn as exemplary of new kinds of artistic practice and new kinds of politics, while in 'Thinking Red' Emily Apter looks to the reappearance of 1960s' icons of radicalism in recent contemporary art as forms of ethical militance. For Rancière, critical contemporary art characterised by his notion of dissensus is available in four broad forms: the joke, the collection, the invitation (for example as described in Bourriaud's relational aesthetics) and the mystery, in which diverse forms are woven together through the 'fraternity of the metaphor'. (47)

However, the spectre of aesthetics' essential paradox continues to threaten art's political power, especially when art is remade into an ethical activity that is asked to fulfil a social function: to repair damaged social bonds or empower threatened identities. While the essays in Communities of Sense argue for the radical potential for equality and heterogeneity that exists within aesthetic fields, they also argue that this potential can only be activated by aesthetic strategies that act on the terms and limits of argument. To the recent trend in contemporary art to make explicitly political work Rancière has this warning: 'art does not do politics by reaching the real. It does it by inventing fictions that challenge the existing distribution of the real and the fictional'. (49) 
Lachlan MacDowall is a researcher in the Centre for Cultural Partnerships, Faculty of the VCA and Music, University of Melbourne. He is the principal researcher on a three-year ARC Linkage grant investigating aesthetic evaluation in communitybased arts projects.

-NOTES

${ }^{1}$ See Tony Bennett, Outside Literature, Routledge, London \& New York, 1990. 